\title{
CHARLES BONNET SYNDROME WHERE IS THE DIAGNOSTIC FRONTIER?
}

P. Melo-Ribeiro ${ }^{1}$, J.M. Cunha ${ }^{1,2,3}$, D. Palma ${ }^{1}$, M. Mota-Oliveira ${ }^{1}$.

${ }^{1}$ Centro Hospitalar Universitário do Algarve, Departamento de Psiquiatria e Saúde Mental, Faro, Portugal.

${ }^{2}$ Faculdade de Medicina da Universidade de Lisboa, Instituto de Medicina Molecular, Lisboa, Portugal.

${ }^{3}$ St. George's- University of London, Neuroscience Research Centre, London, United Kingdom.

SOME OF THE PROPOSED DIAGNOSTIC CRITERIA THROUGHOUT TIME

\begin{tabular}{|c|c|c|c|c|c|}
\hline & $\begin{array}{l}\text { Bonnet C. } \\
\text { (1769) }\end{array}$ & $\begin{array}{l}\text { de Morsier G. } \\
\text { (1936) }\end{array}$ & $\begin{array}{l}\text { Podoll K. et al. } \\
\quad(1989)\end{array}$ & $\begin{array}{l}\text { Teunisse et al. } \\
\quad \text { (1995) }\end{array}$ & $\begin{array}{l}\text { Menon et al. } \\
\quad(2003)\end{array}$ \\
\hline Visual hallucinations & $\theta$ & & & 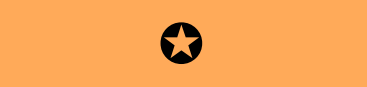 & \\
\hline \multicolumn{6}{|l|}{ Elderly person } \\
\hline Loss of visual acuity / Ocular disease & & & $\mathbf{\Delta}$ & & $\mathbf{\Delta}$ \\
\hline Insight into the unreality of the hallucinations & & & & * & \\
\hline \multicolumn{6}{|l|}{ Intact mental function } \\
\hline \multicolumn{6}{|l|}{ No psychiatric or neurological diseases } \\
\hline \multicolumn{6}{|l|}{ No additional delusions } \\
\hline No hallucinations in other senses & & & & & \\
\hline $\begin{array}{l}\text { - Diagnostic criteria used to define the syndror } \\
\text { - Description of the diagnostic criteria more co }\end{array}$ & ual among & $\begin{array}{l}\text { uthor. } \\
\text { ent authors. }\end{array}$ & $\begin{array}{l}\text { - Total or partia } \\
\text { - May or may } n\end{array}$ & $\begin{array}{l}\text { nsight. } \\
\text { have. }\end{array}$ & cified as \\
\hline
\end{tabular}

THE CURRENTLY MOST ACCEPTED PATHOPHYSIOLOGIC THEORY

VISUAL SENSORY DEAFFERENTATION OF THE VISUAL ASSOCIATION CORTEX

\section{PATIENT 1}

, 87 years old, autonomous for daily life activities. Medical history of loss of visual acuity due to cataracts, worsened after cataract surgery 2 months before. No past psychiatric history. The patient was hospitalized in the Internal Medicine's infirmary due to an atrial fibrillation with rapid ventricular response. During the perfusion of amiodarone, she became agitated and experienced visual hallucinations. An Liaison Psychiatry's observation was requested to manage an hyperactive delirium. The patient referred "since my vision got worse, I began to see the walls filled with flowers and a house that wasn't mine" (sic). She also mentioned "they only bother me because they get in the way of what I'm doing, but they aren't real, they are hallucinations", further stating "it became even worse after my eye surgery, I couldn't do my usual routine" (sic). The patient displayed full insight for her visual phenomena and no other psychopathological findings, including cognitive impairment. She was discharged with Quetiapine $25 \mathrm{mg}$ daily. In ambulatory, the patient remained assymptomatic and with no need for use of medication.

\section{DISINHIBITION OF THE OCCIPITAL CORTEX}

HYPEREXCITABILITY AND SPONTANEOUS FIRING OF THE OCCIPITAL CORTEX

\section{PATIENT 2}

, 83 years old, dependent for daily life activities, in a nursing home. Medical history of significant loss of visual acuity due to a right eye (RE) enucleation and left eye (LE) cataract with subsequent surgery. She had her left leg amputated in 2014 and displays a mild cognitive impairment, evident since 2015 . No past psychiatric history.

The patient was admitted in the emergency room due to a change in her normal behavior. When observed by a psychiatrist, she affirmed "since I lost my leg I see ghosts, a lot of girls eating from little bowls" (sic), adding "there are 2 man in Paderne, Satan and a demon, with a big car, and they grab on to the blind" (sic). These hallucinations occurred mainly in the evening. The patient also states "they speak to each other, but I don't hear them" (sic). The lack of insight and a poor speech centered on her concern about the mentioned hallucinations are clear. She was discharged with Quetiapine 50-100mg daily. In ambulatory, the patient maintained the hallucinations but her behavior was more adequate, with occasional initial insomnia and nightly agitation.

\section{ARE THE MOST CONSENSUAL DIAGNOSTIC CRITERIA MET IN BOTH CASES?}

\begin{tabular}{|c|c|}
\hline Complex visual phenomena & Complex visual phenomena \\
\hline Significant loss of visual acuity (after cataract surgery) & WITH cognitive impairment \\
\hline WITH insight & Significant loss of visual acuity (RE enucleation + LE cataract surgery) \\
\hline
\end{tabular}

BUT THE FINAL DIAGNOSIS WAS THE SAME: CHARLES BONNET SYNDROME

\section{CONCLUSION}

Further investigation into Charles Bonnet Syndrome's pathophysiology is needed for understanding if these visual phenomena, when having cognitive impairment and/or lack of insight, are physiologically the same, which could help to define its official diagnostic criteria. Despite its benign prognosis, patients can experience distress, often associating hallucinations with mental disorders. Therefore it's important to raise awareness to this condition among clinicians because even when Patient 1 presented with criteria considered the most consensual among authors, the diagnosis was delayed by months, having only been recognized when actively asked in the context of an unrelated hyperactive delirium. 